\title{
Cold-induced vasodilation
}

\author{
Hein Daanen
}

Accepted: 2 December 2008 / Published online: 19 December 2008

(C) The Author(s) 2008. This article is published with open access at Springerlink.com

Dear editor,

In this letter I would like to challenge the correctness of the term cold-induced vasodilation (CIVD) in a recent paper of Flouris et al. (2008) in this journal.

The first author who described CIVD was Sir Thomas Lewis, who observed that skin vasodilation occurred in the fingers 5-10 min after exposure to cold (Lewis 1930). He found that this reaction did not occur when the water temperature in which the fingers were immersed was higher than $18^{\circ} \mathrm{C}$. The lower the temperature, the more marked the reaction was. Most experiments conducted since this time has used water temperatures of 0,5 or $8^{\circ} \mathrm{C}$ to evoke CIVD (Daanen 2003).

It is also possible to evoke CIVD responses using exposure to cold air. Kramer and Schulze (1948) observed that the timing of the CIVD responses was similar for ice water bath immersion and exposure to $-18^{\circ} \mathrm{C}$ air in a still air box. They also observed that while most subjects showed a CIVD response in ice water, the response was often absent when the fingers were exposed to cold air. More recent studies confirmed that the good reproducibility of CIVD in water (O'Brien 2005) and the poor reproducibility of CIVD in cold air, in particular in the toes (Cheung and Mekjavic 2007; Van der Struijs et al. 2008). Wind speed is an important factor that increases the number of evoked CIVD responses; Brajkovic and Ducharme (2004) showed that the

\section{H. Daanen}

VU University Amsterdam, Amsterdam, The Netherlands

H. Daanen $(\square)$

TNO Human Factors, Soesterberg, The Netherlands

e-mail: hein.daanen@tno.nl number of evoked CIVD responses increased from 3\% at $2 \mathrm{~m} / \mathrm{s}$ wind to $53 \%$ at $8 \mathrm{~m} / \mathrm{s}$ wind speed.

In the study of Flouris et al. (2008), 10 subjects were exposed to a cold environment $\left(-20^{\circ} \mathrm{C}\right)$ dressed in arctic clothing including thin gloves and arctic mittens and the finger temperatures were monitored. The term CIVD was used to describe the observed changes.

However, in this study, the extremities were not exposed to cold and the term CIVD thus seems inappropriate. The finger temperatures ranged from 7.2 to $33.5^{\circ} \mathrm{C}$ and the observed fluctuations during the experiment did not resemble the typical cyclic CIVD reaction. Although one cannot rule out that some CIVD may have occurred for temperatures just above $7.2^{\circ} \mathrm{C}$, it is more likely that the observed temperature fluctuations are attempts of the body to release body heat through the fingers as a part of the normal thermoregulatory process; rather than an expression of CIVD. The mean body temperature (weighted average of core and mean skin temperature) fluctuated around $36.5^{\circ} \mathrm{C}$, which is relatively high and stresses the need to release body heat. It is well documented that the finger blood flow shows a sudden increase above a certain threshold in body core temperature and is modified by mean skin temperature (Wyss et al. 1974; Wenger et al. 1975; Wyss et al. 1975; Daanen et al. 1992).

In summary, the observed fluctuations in finger skin temperature in the paper of Flouris et al. (2008) should not be termed CIVD, and are better attributed to heat loss mechanisms that depend on body core temperature and mean skin temperature.

Open Access This article is distributed under the terms of the Creative Commons Attribution Noncommercial License which permits any noncommercial use, distribution, and reproduction in any medium, provided the original author(s) and source are credited. 


\section{References}

Brajkovic D, Ducharme MB (2004) Cheek skin temperature and thermal resistance in active and inactive individuals during exposure to cold wind. J Therm Biol 29:831-837. doi:10.1016/j.jtherbio. 2004.08.068

Cheung SS, Mekjavic IB (2007) Cold-induced vasodilatation is not homogenous or generalizable across the hand and feet. Eur J Appl Physiol 99:701-705. doi:10.1007/s00421-006-0383-6

Daanen HAM (2003) Finger cold-induced vasodilation: a review. Eur J Appl Physiol 89:411-426. doi:10.1007/s00421-003-0818-2

Daanen HAM, Wammes LJA, Lotens WA (1992) The threshold in esophageal temperature for hand blood flow. In: Proceedings of the fifth international conference Environmental Ergon, Maastricht, pp 222-223

Flouris AD, Westwood DA, Mekjavic IB, Cheung SS (2008) Effect of body temperature on cold induced vasodilation. Eur J Appl Physiol 104:491-499. doi:10.1007/s00421-008-0798-3

Kramer K, Schulze W (1948) Die Kältedilatation der Hautgefäße (cold induced vasodilation of skin blood vessels). Pflugers Arch 250:141-170. doi:10.1007/BF00363739
Lewis T (1930) Observations upon the reactions of the vessels of the human skin to cold. Heart 15:177-208

O'Brien C (2005) Reproducibility of the cold-induced vasodilation response in the human finger. J Appl Physiol 98:1334-1340. doi:10.1152/japplphysiol.00859.2004

Van der Struijs NR, Van Es EM, Raymann RJEM, Daanen HAM (2008) Finger and toe temperatures on exposure to cold water and cold air. Aviat Space Environ Med 79:941-946. doi:10.3357/ ASEM.2258.2008

Wenger CB, Roberts MF, Nadel ER, Stolwijk AJ (1975) Thermoregulatory control of finger blood flow. J Appl Physiol 38:1078-1082

Wyss CR, Brengelmann GL, Johnson JM, Rowell LB, Niederberger M (1974) Control of skin blood flow, sweating and heart rate: role of skin vs. core temperature. J Appl Physiol 36:726-733

Wyss CR, Brengelmann GL, Johnson JM, Rowell LB, Silverstein D (1975) Altered control of skin blood flow at high skin and core temperatures. J Appl Physiol 38:839-845 